\title{
The Influence of the Exercise Programs on the Boy's Self-Concept
}

\author{
Dao Chanh Thuc* \\ Department of physical education, Vietnam
}

ISSN: 2637-7934

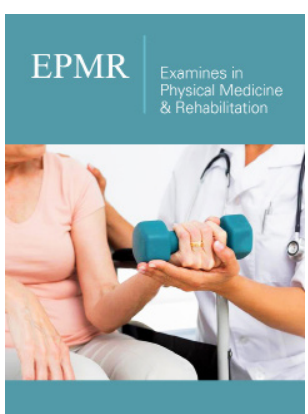

*Corresponding author: Dao Chanh Thuc, Department of physical education, Vietnam

Submission: 価 May 07, 2019

Published: 侮 May 16, 2019

Volume 2 - Issue 4

How to cite this article: Dao C T. The Influence of the Exercise Programs on the Boy's Self-Concept. Examines Phy Med Rehab.2(4). EPMR.000541.2019. DOI: 10.31031/EPMR.2019.02.000541.

Copyright@ Dao Chanh Thuc, This article is distributed under the terms of the Creative Commons Attribution 4.0 International License, which permits unrestricted use and redistribution provided that the original author and source are credited.

\begin{abstract}
This study is to investigate the effectiveness of an exercise program for children from 10 to 11 years old. In this study, 30 subjects were divided into two groups of equal control and training. After completing the procedure, the participants in the training group performed the gymnastics training program for 12 weeks and the control group did nothing. Data collection tool is a demographic questionnaire and a scale of self-concept Piers-Harris. Kolmogorov-Smirnov test is used to test the normal distribution of samples. The research results show that in the training group, the size of the concept of self and the general selfconcept of children before and after exercise instrument increased significantly. The results also show that the size of happiness and satisfaction of children, both in the control group and in the training group, is significantly different. The study concluded that a training program in the field of gymnastics training has significantly increased the level of self-concept of children.
\end{abstract}

Keywords: Self-concept; Exercise program; Children boys

\section{Introduction}

Participating in physical activities, in addition to having a positive impact on physical characteristics, also affects mental qualities, and it is obvious that physical activity also has physiological and psychological benefits. Compared to traditional interventions such as psychotherapy, psychological, social and pharmaceutical interventions, physical activity has some relatively cost-effective side effects Amin [1]. Moreover, physical activity can have beneficial effects in cardiovascular disease, diabetes, high blood pressure, cancer, osteoporosis and obesity. Research in this area shows that physical activity can improve mental health Ankinson [2]. Nolis says that the physical image (the concept of physical self) includes the person's emotions, behaviors and values to the person and how to look at an individual's appearance and all the emotions forming their physical image Baqaian [3]. Many factors such as speed and quality of communication between children and parents, inspiring and encouraging family members, especially parents Brown [4], social interactions such as reactions of others, age, sex and sports activities, affecting the concept of self. A person has a strong and positive self-concept, compared to a person with a poor self-concept, having a completely different view of the world Gulmans [5]. The concept of self makes the person more sensitive to his own information and makes it easier to encrypt and retrieve Masoud [6]. The reason for this is that personal information is analyzed more deeply and carefully, and the information of the most self-organizing information networks lies in the memory of individuals, and the more often the information is, the more the stronger the reminder Hassmén [7]. The concept of physical self is a branch self-concept that indicates awareness and self-evaluation of their own bodies. Many studies have shown that there is a positive and meaningful relationship between sports activity and self-concept. Wells and his colleagues in a study called: The Effect of a 12-week resistance exercise program on power, body composition and concepts, shows the resistance of working exercises to work. positive action to people self-awareness Jais [8]. In this study, with the presence of two samples of high school students 305 and 365, showed that the tool was considered, including miniatures related to strength, body fat, physical activity, endurance , sports, coordination, health, appearance, flexibility, self-concept and self-esteem in general, are valuable enough to identify the self-conceptual elements of the body and the presentation model of The concept of the body itself has a multi-dimensional nature. The external 
effect of this tool has also been studied in another study, and it has shown that its ranges are significantly correlated with physical fitness items Lin [9]. Confirmation, approval and encouragement of family members, especially parents, confirms a positive self-concept in children. One of the important factors in the development of self-concept is a replica copy with patterns; That means the child copies with important people in his or her life and chooses them as role models or behavioral models. Copies make your image altered; means that the person feels that he has become like his model [6]. In general, the stability of the concept itself depends more on the connection between the concept of the original self that was born in the beginning, especially in the home environment and the concept of secondary self-formed later. This Planet [10]. Except for the stability of self-concept in general, the cohesion between different types of self-concept is also important for mental health people. In Roger's theory, one of the main concepts is the harmony between the concept of the basic self and the concept of ideal self; The greater the distance between these concepts, the greater the conflict between the actual possibilities and the ideal of the individual Pourhossein [11]. In such conditions, people can adapt to the environment and enjoy a satisfied life. Such a person has a notion of incoherent or negative self. Conversely, if the gap between self-concepts is low and some types of combinations exist between different self-concept of individuals, people will have more peace and mental health Pronk [12]. A study, entitled; Has been done the concept of self-comparison of sports and non-athletic students. The object of this study was 200 students between the ages of 16 and 19 who were randomly divided into two groups of 100 people including athletes and non-athletes. To assess the degree of self-concept in subjects, the California personality test was used Richards [13]. The test results for two independent groups show that there is a significant difference between the notion of self-athletes and non-athletes, that is, athletes have higher self-concept and more stable. However, there are studies that show a lack of significant effects of exercise on self-concept Saatchi [14]. A study, entitled: Other Determining the correlation between the concept of physical self and the selection of physical factors and physical activity of students, was done. The object of this study is 100 Isfahan University female students with ages 19-25. The tool used to collect information about standard autonomic variables Svoahulavard [15] is a physical self-describing questionnaire containing 24 questions including four questions about strength, endurance, coordination and calculation. flexible. Tool to measure the fitness and physical activity of different people, respectively four previous strength tests, aerobic balance, coordination, sitting and reaching out; and the questionnaire is an indicator of physical activity Velez [16]. To clarify the impact of sports activities, especially gymnastics, for the concept of self, the researcher sought to answer the question of whether an exercise course affects the concept. itself and its range affect children from 10 to 11 years old or not.

\section{Material and Methods}

In this study, dependent variables, self-concept, were measured in participants before and after applying independent variables (exercise program). The statistical population of this study is all boys from 10 to 11 years old. The sampling method is simple random sampling, 40 people were selected in the first stage and the last 10 were excluded from the study for many reasons such as unavailability and lack of cooperation as well as sports records in other sports fields and 30 people were chosen as the final model. The specific characteristics of the subjects are shown in Table 1. All selected subjects do not have cardiovascular disease, diabetes, etc. and consent letters were taken from their parents, and the children were asked if they wanted to participate in the study. In addition, their demographic questionnaire, i.e. sports records and personal information, as well as physical health requirements have been completed. Participants were randomly divided into two training and control groups with 15 individuals for each group. The subjects of both groups fill in Pier-Harris's demographic questionnaire and self-concept scale. Demographic questionnaires include general information of participants and their parents, such as age, sports activity profile, gender, family economic status and parental education. The validity and reliability of this scale were made for a random sample of 1010 people. The retest method and the split method were also applied as a valid calculation index. The coefficients of this calculation are reported as 0.81 Dao Chanh T [17]. In addition, the validity of the self-acceptance scale is determined as follows: The content of the self-concept scale is determined by translation and finds that all questions express very similar thoughts reflected on the original scale and the tool has the level High officiality and content effect. To ensure simultaneous validity of the self-concept scale, the correlation of scores for each sub-scene is taken together, which indicates that all correlations are significant at 0.01 level. According to Saatchi and et al, this tool, especially a child-related tool, has a strong reliability of 0.73 for children who go to school for more than 4 months [10]. In addition, this tool is effective at the same time, this has been demonstrated by a significant correlation with the scale of Pierson-Harris concept itself, for children.

Table 1: Personal characteristics of subjects in training and control groups.

\begin{tabular}{|c|c|c|}
\hline Groups/Characteristics & Control Group (M \pm SD) & Training Group (M \pm SD) \\
\hline Age (year) & $10.72 \pm 0.909$ & $10.74 \pm 1.030$ \\
\hline Height $(\mathrm{cm})$ & $142.4 \pm 2.11$ & $143.1 \pm 1.86$ \\
\hline Weight $(\mathrm{kg})$ & $35.32 \pm 3.05$ & $34.85 \pm 2.47$ \\
\hline
\end{tabular}




\section{Research Results}

12 weeks of exercise has been assigned for group participants. The actual program is presented in Table 2.

As a result, in Table 2, the control group did not perform any exercises during this period. The duration of each training session for the training group is 45 minutes in 12 weeks. The exercise time is 6 to 7 p.m. The program is conducted under the supervision of fitness coaches. After completing the training period (12 weeks), once again both the training and control groups completed the demographic questionnaire and Piers-Harris self-concept scale. After answering the questions. The questions are collected by researchers for statistical activities. Descriptive statistics are used to study central trends and data distribution [17]. In addition, Kolmogorov-Smirnov experiment was used to study the natural distribution of data. Correlation test has been applied to test the significant difference of means of measurement variables before testing and after testing. In addition, independent t-testing with SPSS 20.0 software was used to test significant differences between the two training and control groups. To display the significance level of $\alpha=0.05$ has been considered. The characteristics of the study object are expressed as the average standard deviation in Table 1.

Table 2: Practice program of the training group.

\begin{tabular}{|c|c|c|}
\hline No & Type of Activity & Activity Duration \\
\hline 1 & $\begin{array}{l}\text { General body heats up: } \\
\text { Stretching action } \\
\text { Slow down the movement }\end{array}$ & 10 minutes \\
\hline 2 & $\begin{array}{l}\text { Expert to heat the body } \\
\text { Move power using the ladder, stretching from the horizontal bar } \\
\text { Climb up and down the rope }\end{array}$ & $\begin{array}{l}5 \text { minutes } \\
5 \text { minutes } \\
10 \text { minutes }\end{array}$ \\
\hline 3 & $\begin{array}{l}\text { Education program: } \\
\text { Front rolling, rolling back, balancing walls, carousel, jumping and landing, moving position within, going on balanced } \\
\text { wood, jumping from balanced wood }\end{array}$ & 30 minutes \\
\hline 4 & Cooling down, Gentle walking and stretching exercises & 10 minutes \\
\hline
\end{tabular}

Results Table 1 shows the specific characteristics of the training and control groups divided into three parts, age, height and weight. The results of Table 1 show that the age of both groups of subjects has the same difference and this applies to the height of the objects. In addition, the weight in both groups is similar.
According to Table 3 and Figure 1, the means of general scale concept itself in the control group fell in the following test, compared with the previous test, while in the training group, means of total self-concept scale in posttest increases, compared to previous tests (Figure 1).

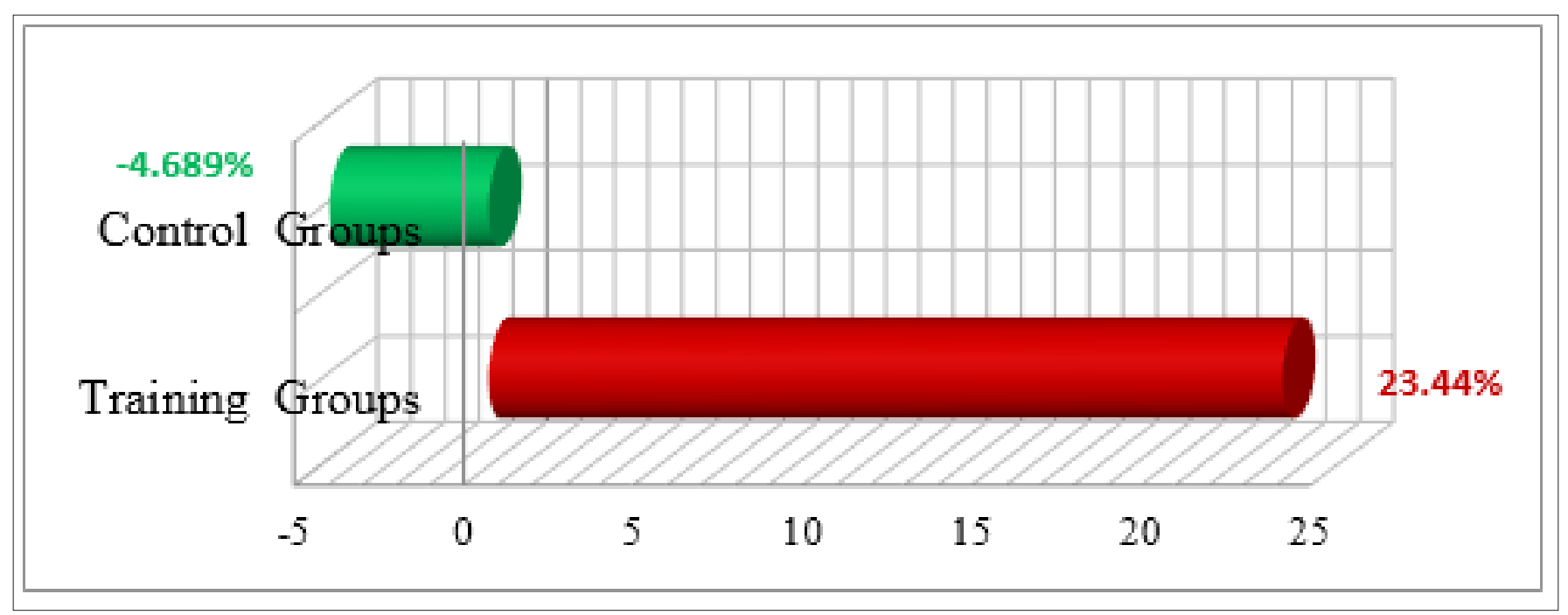

Figure 1: 
Figure 1: Total value growth of the concept of self-test before / after testing in control and training groups.

As the result of Table 4 shows, in the training group, the total number of dimensions of self-concept in the following test has in- creased significantly compared to the previous test. However, according to the results of statistical tests, in the control group, the average value of all aspects of self-concept, except happiness and satisfaction, did not increase significantly in the following experiment. compared to the previous test.

Table 3: Shows the total value of the self-concept being the average \pm standard deviation in the two measurement periods.

\begin{tabular}{|c|c|c|r|}
\hline Statistical index Groups & Groups & Mean & SD \\
\hline \multirow{2}{*}{ Training } & Pre-test & 47.12 & \pm 2.181 \\
& Post-test & 59.63 & \pm 2.732 \\
\hline \multirow{2}{*}{ Control } & Pre-test & 46.27 & \pm 3.013 \\
& Post-test & 44.15 & \pm 2.407 \\
\hline
\end{tabular}

Table 4: Average value of self-concept size in training and control groups.

\begin{tabular}{|c|c|c|c|}
\hline Dimensions & Groups & Pretest (M \pm SD) & Post-Test (M \pm SD) \\
\hline \multirow{2}{*}{ Behavioral dimension } & Training & $5.8 \pm 0.903$ & $12.75 \pm 0.938$ \\
\cline { 2 - 4 } & Control & $5.7 \pm 1.117$ & $14.6 \pm 1.086$ \\
\hline \multirow{2}{*}{ Rational and educational situation dimension } & Training & $12.10 \pm 1.373$ & $11.76 \pm 1.181$ \\
\cline { 2 - 4 } & Control & $12.11 \pm 1.463$ & $14.05 \pm 0.775$ \\
\hline \multirow{2}{*}{ Appearance and awareness } & Training & $8.85 \pm 0.726$ & $8.25 \pm 1.020$ \\
\cline { 2 - 4 } & Control & $8.70 \pm 1.021$ & $5.85 \pm 1.109$ \\
\hline \multirow{2}{*}{ Anxiety dimension } & Training & $12.75 \pm 1.189$ & $11.97 \pm 1.210$ \\
\cline { 2 - 4 } & Control & $12.69 \pm 1.376$ & $5.41 \pm 1.131$ \\
\cline { 2 - 4 } & Training & $3.75 \pm 0.926$ & $3.52 \pm 0.823$ \\
\cline { 2 - 4 } & Control & $4.60 \pm 0.843$ & $6.95 \pm 1.882$ \\
\hline \multirow{2}{*}{ Popularity dimension } & Training & $4.55 \pm 0.865$ & $3.50 \pm 0.823$ \\
\hline
\end{tabular}

\section{Discussion and Conclusion}

In this study, the effectiveness of a sports exercise program for male children has been investigated by themselves. The research results show that exercises have a statistically significant effect on all aspects of the concept of children themselves. As a result, the average value of the post-test self-concept increased significantly compared to the pre-test, which can be attributed to the use of an independent variable, i.e. exercise exercises because of the training program. Fitness develops the infrastructure elements of self-concept including strength, endurance, coordination and flexibility. The impact of various exercises and training programs, including aerobic exercises and anaerobic and general health programs, for increasing the concept of self and body image in other studies each other, confirm each other's results in most cases and support improving the concept itself through physical activity. Psychologists believe that if exercise is done in a healthy environment, it can improve people's natural spirit and eliminate inferiority and facilitate communication with other people in the commune. Assembly and living with them is easier. Physical activity and exercise when performed by similar age groups cause some potential talent if individuals, disagree with individual activities, thrive in the sports environment. In addition, the study results show that there is a significant difference between the effectiveness of the exercise program for male self-sufficiency in testing before and after testing, consistent with the results of Many studies [6]. Current research has examined the impact of physical activity, errand activity and the use of a different exercise program with varying intensity and time. However, all showed a positive and meaningful correlation between physical activity and body image. In this study, groups, perform physical activity, i.e. aerobic activity, jogging and gymnastics, are compared with the demonstration group, make the game easy, draw pictures, sing and go sets, and other proof groups, do not have physical or recreational activities. They found that there was a significant difference between aerobic activity and the self-concept group. The results clearly show the interest and influence of aerobic activity on growth and self-concept development compared to other physical and non-physical education programs. According to research results, there is a significant difference between the impact of the physical education program on the behavior of male children in the previous test and the following test. In addition, planned behavioral theory is very useful in understanding and explaining sports behavior, and it shows attitudes towards exercise, subjective standards of exercise and control. Sports-aware behavior is correlated with exercise trends. In addition, the tendency to exercise and control the perceived behavior of exercise is correlated with exercise Hutzler 
[18]. Pronk notes that intense exercise can have many benefits in mood and behavior, and it is related to stress, stress and increased confidence [14]. According to research results, there is a significant difference between the impact of the physical education program on the reasonable and educated status of male children in the previous test compared to the following test. According to the researchers, the intelligence and memory of people who run more slowly than others and this amount is reduced by stopping the exercises.

According to the study results, there are significant differences between the impact of the exercise program on the appearance and attitude of male children in the trial before and after the experiment. The results of this study contradict the results of the study [4] and have similarities with the study of [6], probably due to the inconsistency of the statistical population that in Ghadiri's research, It was done on the physical research of 13 to 18 year old boys with cerebral palsy, but in this study, healthy children aged 10 to 11 years were studied. According to the study results, there is a significant difference between the impact of the exercise program for male children the level of anxiety in the previous test and the following test. In another study, it was found that with intense exercises, serious behavioral changes such as anxiety, stress, depression and increased self-esteem occurred in individuals, and lessons learned. Aerobic exercise can improve self-esteem and reduce depression Penedo [19]. According to research results, there is a significant difference between the impact of the gymnastics training program on the common aspect of children in the pre- and post-test trials. One of the most widely held beliefs about exercise is that sport benefits athletes in many ways. Such effects may be temporary or permanent and may be accurate for all parts of society. One of the possible benefits from sports participation is the positive effect on the development of self-concept. The research results confirm that the effectiveness of the exercise program will have a positive impact on the self-concept of male children aged 10 to 11 years. Overall, the findings suggest that a 12 -week fitness program has a significant and extraordinary effect on the concept of self in general and all dimensions of self-concept in children.

\section{References}

1. Amin Yazdi SA (2012) Studying the content of self-concept in adolescent girls and boys. Master's degree thesis, Faculty of Education and Psychology, University of Tehran, Iran.

2. Ankinson H (2014) The background of psychology. Growth Publishing, Georgia.

3. Baqaian M (2010) The effects of gender and physical activity level on physical self-concept of students in the secondary education. Quart J Edu Innov 12(47).
4. Brown HE, Pearson N, Braithwaite RE, Brown WJ, Biddle SJ (2013) Physical activity interventions and depression in children and adolescents. Sports Med 43(3): 195-206.

5. Gulmans VA, Meer K, Brackel HJ, Faber JA, Berger R, et al. (2008) Outpatient in children with cystic fibrosis: physiotherapy effect, perceived competence and acceptability. Pediatr Pulmonol 28(1): 39-46.

6. Masoud KD (2018) The effect of a gymnastic exercise program on the boy's self-concept. European Journal of Sports \& Exercise Science 6(2): 74-81.

7. Hassmén, P, Koivula N, Uutela A (2012) Physical exercise and psychological well-being: a population study in Finland. Prev Med 30(1): 17-25.

8. Jais C (2009) Self-concept of students learning disabilities: a meta-analysis. School Psychol Rev 31(3): 405-427.

9. Liu M, Wu L, Ming Q (2015) How does physical activity intervention improve self-esteem and self-concept in children and adolescents? evidence from a meta-analysis. PLoS One 10(8): 0134804.

10. Planet T (2008) Physical fitness and enhanced psychological health. Current Psychology 9(1): 3-24.

11. Pourhossein R (2008) An investigation of the concept of self-conception of children 6-11 years old, Tarbiat Modares University, Iran.

12. Pronk N (1995) Maximal Exercise and cute mood response in women. Physiol-behavor 57(1): 1-4.

13. Richards R (2006) Self-concept and physical activity, across sectional study. The Journal Mischigan University, USA, 7: 405.

14. Saatchi M (2011) Psychological tests.

15. Svoahulavard C (2015) Exercise psychology (with psychological and social approach). Physical Education Organization Publication.

16. Velez A, Golem DL, Arent SM (2010) The impact of a 12-week resistance training program on strength, body composition, and self-concept of Hispanic adolescents. J Strength Cond Res 24(4): 1065-1073.

17. Dao Chanh Thuc (2018) Measurement in sports. Lap Lambert Academic Publishing, USA.

18. Hutzler, Y Chacham A, Bergman U, Reches I (2014) Effects of a movement and swimming program on water orientation skills and self-concept of kindergarten children with cerebral palsy. Percept Mot Skills 86(1): 111-118.

19. Penedo FJ, Dahn JR (2013) Exercise and well-being: a review of mental and physical health benefits associated with physical activity. Curr Opin Psychiatr 18(2): 189-193. 